\section{Congenital Fusion of Two Segments of the Sigmoid Colon}

Congenital abnormalities of the colon are rare findings, and are particularly unexpected as a primary diagnosis in elderly patients. Colonoscopy was performed in an 82-year-old woman due to constipation and subileus. Surprisingly, a colonic bifurcation was found after visualization of a sigmoid colon segment with a wide lumen (Figure 1). When the colonoscope was advanced further through one of the two connecting lumina, the endoscope was encountered again at the $40 \mathrm{~cm}$ mark, i.e., a loop $40 \mathrm{~cm}$ long had been explored. The patient had never undergone a laparotomy. Further inspection of the intestinal segment situated distally showed the hint of a raphe in the middle of the circumference and a further ostium at the distal end of the wide segment, through which the colonoscopy was completed without further abnormal findings.

Radiological contrast imaging of the colon then revealed a sigmoid segment with a lumen that was twice as wide as the rest of the colon. The blind loop opened into this broad segment, and the distal end divided, one arm passing into the descending colon and one arm running distally in the direction of the rectum (Figures $\mathbf{2}$, 3). The left and the right part of the fused segment showed separate contraction waves, showing also that the two parts were controlled by distinct parts of the enteric nervous system. Tubular duplication of the colon, which can also lead to fecal retention, was therefore not present (1), but a congenital fusion of two sigmoid segments situated side by side. This malformation has not previously been mentioned in the literature.

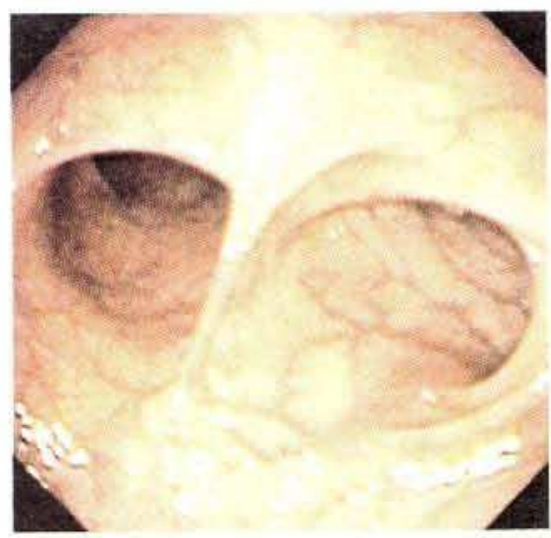

Figure 1: Colonoscopic view from the wide segment on the bifurcation, with normal wide openings into the blind loop.

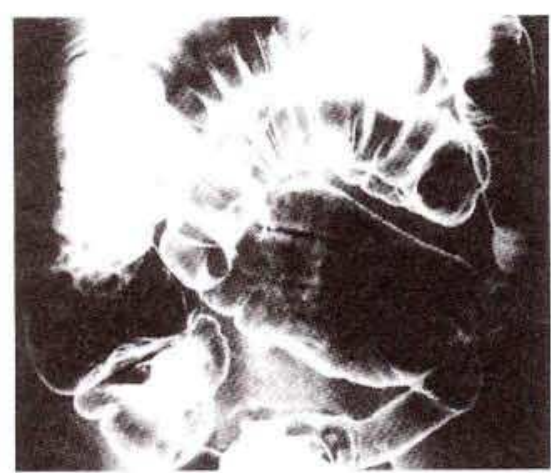

Figure 2: Radiological contrast imaging the fused segments of the sigmoid colon.

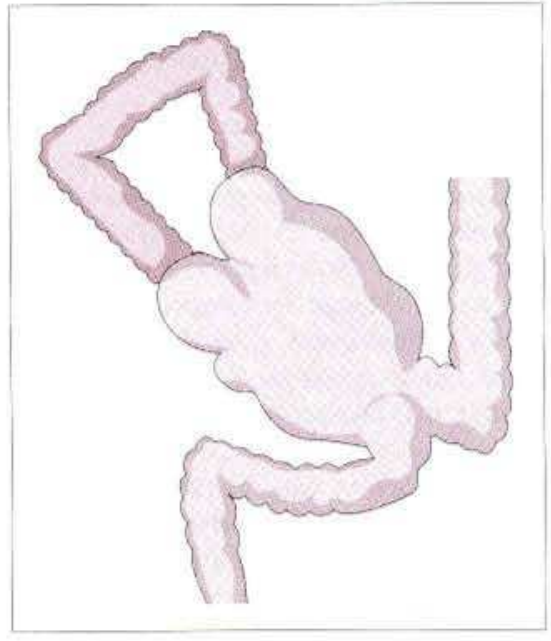

Figure 3: Schematic illustration of the radiological findings.

The most probable hypothesis explaining the genesis of this malformation is that two segments lying side by side grew together or adhered in the early embryonic phase, in which the intestinal lumen is occluded by epithelial proliferation. During the subsequent phase of recanalization of the intestinal lumen, in which longitudinal vacuoles form the new intestinal lumen by fusion (2), a common lumen for the segments that had grown together was formed. The still barely recognizable raphe therefore constitutes the rudimentary remnant of the two disintegrated intestinal walls that had grown together. The patient did not show any further abnormalities, and was able to leave the hospital again without symptoms after laxative treatment.

\section{K. J. Goerg, M. Wybierala}

Dept. of Internal Medicine, St. Josef Hospital, Wuppertal, Germany

\section{References}

1. Yousefzadeh DK, Bickers GH, Jackson JH Jr, Venton C. Tubular colonic duplication: review of 1876-1981 literature. Pediatr Radiol 1983; 13: 65-71.

2. Anders HE. Die Missbildungen des Darmkanals und der Verdauungsdrüsen, einschliesslich der Kloakenmissbildungen. In: Schwalbe E, Gruber GB, editors. Die Morphologie der Missbildungen des Menschen und der Tiere, 3: Die Einzelmissbildungen. Jena: Fischer, 1913: 375-425.

Corresponding Author

K. J. Goerg, M. D,

Medizinische Klinik mit Subdisziplin Gastroenterologie

Krankenhaus St. Josef

Bergstrasse 6-12

42105 Wuppertal

Germany

Fax: $+49-202-485-2209$ 